\title{
Esfera Pública y temas de conflicto
}

\section{Public Sphere and Conflict Issues}

José Francisco Serrano Oceja. Universidad CEU San Pablo

Resumen:

La relación entre sociedad y política tiene un espacio privilegiado en la esfera pública. Los temas de conflicto están sometidos a las leyes sociales impuestas por los medios de comunicación. Pero más allá de los medios de comunicación existen, sobre todo a la hora de abordar cuestiones como la relación entre Religión y Política, unos principios que deben tenerse en cuenta para el adecuado diálogo público.

Palabras clave:

Esfera Pública, Religión, Política, diálogo público, Educación, Medios de Comunicación

Abstract:

The relationship between society and Politics enjoys a privileged area in the public sphere. Conflict issues are subject to the social laws imposed by the Mass Media. But there are some principles to be born in mind beyond the Mass Media when dealing with the relationship between Religion and Politics.

Keywords:

Public Sphere, Religion, Politics, Public Dialogue, Education, Mass media 
¿Es la esfera pública, por su dinámica y procedimientos, un ámbito de franca deliberación racional y un espacio pacífico de acuerdo de libre coacción o es todo lo contrario, un espacio de confrontación permanente y de combustión social y política? ¿Acaso el problema radica en la política, y en los procesos de relación entre la política y la sociedad? ¿ Nos encontramos ante una política sin sociedad, o una sociedad sin política?

Según Habermas (2011: 23), "la política se ha convertido en el código de un subsistema administrativo autosuficiente, hasta el punto de que la democracia corre el peligro de convertirse en una mera fachada que los organismo ejecutivos muestran a sus indefensos clientes".

Ante la actual situación de escepticismo frente a las sensibilidades normativas y el poder legítimo de coacción, resurge la pregunta por lo político. Una pregunta que nos retrotrae al concepto de lo político que para algunos autores es un antídoto contra las tendencias despolitizadoras. Detrás del concepto de lo político, que está en el sustrato del trípode Educación, Medios de Comunicación y Leyes, se encuentra una concepción antropológica, una cosmovisión, un sentido de lo humano. La diferencia establecida por Claude Lefort entre Lo político y La política es relevante para no perdernos. Habrá que referirse principalmente a Lo político y sólo posteriormente a La política en la medida en que nos ayude a entender nuestro mundo vida. Porque si es cierto que nos preguntamos por Lo político lo es porque no somos capaces de desprendernos de la cuestión antropológica. ¿ $\mathrm{O}$ acaso Lo político en educación, en medios de comunicación, en las leyes no es mucho más que político?

Este hecho me recuerda la afirmación de un teólogo contemporáneo que decía que la teología deviene en antropología; la política deviene, inevitablemente, en antropología también. Hemos asistido, en los últimos años, a una campaña sistemática de desprestigio de las propuestas de la política basadas en lo político, denominándolas esencialistas, mientras quienes esto afirmaban implantaban socialmente sus políticas de modernización que también responde a una concepción "esencialista" de Lo político encubierta con talantes de técnica de mercados sociales.

Una cuestión relacionada estrechamente con el binomio antes puesto es la cuestión del Estado moderno y la secularización. El Estado moderno responde, al menos en la historia desde el inicio de la modernidad, por una parte, a los imperativos económicos de lo regulado por el mercado y por otra a la necesidad de apaciguar las cruentas guerras de religión. John Rawls reconoce que la secularización de la autoridad política no ha resuelto por sí sola el problema de la relevancia política de la religión en la sociedad civil. La secularización del Estado no es lo mismo que la secularización de la sociedad. En este sentido se podría pensar que en estos últimos años, en España, hemos asistido a un proceso de secularización intensiva e inducida de la sociedad, dado que quienes son autores de ese proceso consideraban que la secularización del Estado como 
principio de la democracia y de la Transición era un proceso interrumpido. La intensidad de la secularización de la sociedad, a través de leyes que afectaban a la concepción antropológica de la existencia, venía determinada no por una demanda social, sino por un proyecto de convertir nuestro país en la punta de lanza de las legislaciones secularizadoras. Este proceso no era sólo un proceso en La política, sino que partía de un proceso en el ámbito de Lo político, porque innegablemente contenía una concepción antropológica subyacente.

La cuestión radica en que, en este proceso de secularización de la sociedad, la mens actora se topó con la Iglesia. Y mientras que en el mundo globalizado se seguía profundizando, por decirlo de alguna manera, en la intuición de John Rawls de que la constitución liberal misma no debe ignorar las contribuciones de los grupo religiosos que pueden hacer al proceso democrático dentro de la sociedad civil, en España, se construyó la figura del oponente por sistema identificado con la Iglesia, del oponente de la mitología o del mantra público de que la Iglesia representaba la antítesis de la modernidad y de que sus intervenciones en la esfera pública significaban un ejercicio de intromisión en el debate público. Paradójicamente, explícita o implícitamente, se negaba que la Iglesia estuviera preparada para intervenir en la esfera pública por su historia, por sus hábitos, por sus lastres mentales; a lo sumo se llegaba a considerar que una cierta Iglesia sí estaba preparada, y otra no. Se nos ha querido hacer creer que el juego estaba entre Iglesia y políticas sociales.

La cuestión no es la construcción o destrucción de fórmulas mantra, como dice Ch. Taylor (2011: 45), sino entender el reto que planteó Rawls, y al que J. Habermas, y otros, han dedicado no poco tiempo:

"En el debate político público se pueden introducir, en cualquier momento, doctrinas generales razonables, religiosas o no religiosas, siempre que se ofrezcan razones políticas apropiadas (...) para sustentar lo que ellas proponen" (Rawls, 2001: 177).

Lo relevante aquí no sé si es la idea del overlapping consensus entre las diversa doctrinas y visiones del mundo, y del hombre, sino el "uso público de la razón” por parte de esas antropologías articuladas. Es más, según este marco presupuesto, la lealtad democrática depende de aceptar el requisito de la traducción de la argumentación pública desde el punto de vista de la razón pública neutral. La consideración de ciudadanía "plena y de ejercicio" se confiere, por tanto, a quien es capaz -no a quien quiera o no- de traducir sus argumentaciones en el lenguaje de razón pública, incluso de la tecnoestructura política y comunicativa, y por qué no decir educativa. En este sentido habría que preguntarse si la pérdida de lenguajes especializados, al tempo que se construyen otros, no supone una reducción del pluralismo social y una desligación de las raíces contextuales históricas. 
Vayamos a esta cuestión. J. Habermas propugna que todos los ciudadanos deben tener la libertad para decidir si utilizan el lenguaje religioso en la esfera pública. Si lo utilizan deben aceptar que el potencial contenido de verdad de las afirmaciones religiosas se debe traducir a un lenguaje universalmente accesible. Se constituye, por tanto, un filtro institucional para la depuración de la retórica religiosa. Si a esta depuración de la retórica religiosa le añadimos la espiral del silencio, nos encontramos con el pez que se muerde la cola o con el modelo trampa. Con esta propuesta se consigue que todo contenido de valor y toda decisión ejecutiva sea justificada y sancionada por un lenguaje universalmente accesible sin tener que restringir la diversidad polifónica (Habermas, 2011: 35). ¿Es este proceso simétrico o asimétrico? Los ciudadanos no creyentes están obligados, en principio a no descartar las aportaciones de los creyentes, ni a deslegitimarlas, ni a ridiculizarlas, por principio como vacías o sin sentido o pretéritas. Los ciudadanos creyentes y no creyentes deben encontrarse en el uso público de la razón. Las aportaciones de una parte no son menos importantes que las de la otra.

La razón secular, y el lenguaje que sostiene la razón secular, se configura como el único lenguaje viable social y políticamente. Aquí se da una distinción epistémica (Taylor, 2011: 53) Existe una razón secular que todos pueden utilizar y con la cual se pueden llegar a conclusiones; y una razón religiosa, lenguaje especial que podría contradecir la razón secular. Estos supuestos son frágiles dado que no convencerán a menos que los admitas como presupuesto, a saber, la razón religiosa llega a las mismas conclusiones que la razón secular, y es lícita, o llega a conclusiones contrarias, con lo que es perjudicial, y hay que mantenerla al margen. Indudablemente la cuestión es la definición de razón y la comprensión de si existe una única razón, la razón es la misma, o si la razón necesita de una adjetivación. La historia es elocuente sobre el proceso de contextualización de la razón y de su constitución como razón adjetiva y de sus patologías. En este sentido el diálogo Ratzinger-Habremas sigue siendo uno de los diálogos más intelectualmente sugerentes e influyentes de cuantos se han realizado en la época contemporánea.

¿Será políticamente incorrecto si hablamos de las patologías de la razón? Por ejemplo, no seré yo quien defienda íntegramente los postulados de W. T. Cavanaugh, pero ahí está su tesis de que "en lo que se llaman las sociedades "occidentales", el intento de crear un concepto transhistórico y trascultural de religión, que sería proclive naturalmente a la violencia, es uno de los mitos fundacionales que legitiman el estado-nación liberal. El mito de la violencia religiosa ayuda a construir y a marginar a otro religioso, dado al fanatismo, en contraste con el sujeto secular, que es racional y pacificador" (Cavanaugh, 2010: 14).

Un inciso para plantear una cuestión que está en el trasfondo y que nos permite después completar este cuadro de diálogo público, el marco del espacio público. Me refiero a la cuestión de la neutralidad del Estado. 
La secularización en los tiempos actuales probablemente no tiene tanto que ver ya con la separación entre el Estado y la Religión, sino con la cuestión de qué debe hacer el Estado ante la diversidad. Se ha establecido, por parafrasear a Rajeev Bhargava, una “distancia por principio”. En este sentido se podría decir que las sociedades libres requieren un alto grado de confianza entre los individuos; son muy vulnerables a la desconfianza de unos ciudadanos con otros. Crean una distancia por principio que se ha convertido en distancia por sistema y que hacen complejas, a veces perceptiblemente imposibles, las decisiones sobre el bien común. Se podría decir que nos encontramos en la dialéctica entre distancia y Koinonía en la relación con la polis (otra forma de hablar de la naturaleza humana, distancia frente a cercanía sobre la cuestión de la naturaleza).

Ch. Taylor afirma recientemente que "hoy en día la idea de que la neutralidad es básicamente una respuesta a la diversidad encuentra dificultades para abrirse paso entre los "no creyentes" occidentales, extrañamente obsesionados con la religión, a la que consideran algo extraño y tal vez incluso amenazador. Esta postura se alimenta de todos los conflictos, pasados y presentes, de los Estados liberales con la religión, pero también de una distinción específicamente epistémico: el pensamiento religioso es de alguna manera menos racional que el puramente "secular". Esta actitud tiene una base política (la religión como amenaza), pero también otra epistemológica (la religión como defectuoso razonar)” (Taylor, 2011: 55).

No está de más recordar las preguntas que este autor se hacía recientemente a este respecto: ¿Qué razón hay para pensar que la "razón natural" ofrece una especie de esperanto ideológico? ¿Fueron los conciudadanos seculares de Martin Luther King incapaces de entender lo que él defendía cuando abogaba por la igualdad en términos bíblicos? ¿Lo habrían entendido más si hubiera invocado a Kant?Y además, ¿cómo distingue uno el lenguaje secular del religioso? ¿La regla de oro está claramente en uno y en otro?

Plantear estas cuestiones incide en el meollo del paso de la Revelación a la sola razón y por tanto debo adentrarme en las procelosas aguas de la Ilustración. Lo haré sólo para recordar lo que escribía MacIntyre no hace mucho:

"Nótese, pues, que aquello en lo que la Ilustración y sus herederos han fracasado no es en su incapacidad para proveernos de principios y valores morales justificables y consensuados. El fracaso de esas instituciones modernas han sido la encarnación de las mayores esperanzas sociales y políticas de la Ilustración es bastante sorprendente. Y tales instituciones han fracasado según los criterios de la propia Ilustración, puesto que no proporcionan -de hecho lo hacen imposible-los tipos de lectura, conversación y discusión públicas institucionalizadas necesarios para la práctica eficaz del pensamiento racional precisamente acerca de los principios y decisiones referentes a las respuestas a cuestiones tales como: “ ¿cómo ha de va- 
lorarse a la vida humana? O ¿qué responsabilidad se exige de nosotros en nuestras relaciones sociales?” (MacIntyre 2008: 294).

Interesa más desentrañar el estatus de la sola razón, como si la sola razón fuera capaz de resolver ciertas cuestiones político-morales de un modo legítimamente satisfactorio para cualquier pensador honesto y como si las conclusiones sustentadas religiosamente fueran siempre dudosas y, a la postre, convincentes sólo para los que admiten los dogmas. Hay quien puede decir que religión es una ilusión y por tanto lo derivado de ella menos creíble. Pero mientras que no se demuestre esta afirmación no hay razón para sospechar de más de ella. Tengamos en cuenta que cuando nos obligamos a traducir el lenguaje religioso en la esfera de la razón pública estamos asumiendo los principios anteriormente citados, y no ponerlos en duda es una confirmación de su validez acrítica, al tiempo que estamos confirmando lo que nos han dicho que confirmemos.

Una modernidad "que se ha vuelto reflexiva” levanta acta de que el proceso de secularización no sólo ha disuelto el mundo de la fe sino que también ha consumido el a priori teológico que está detrás de las certezas de la razón moderna. La secularización ha erosionado conjuntamente la fe y la razón. Aquí encuentra su razón de ser la reducción spengleriana de Occidente a sus propios límites. Frente a ello se abre la posibilidad de repensar el marco de las libertades modernas y la autonomía del sujeto.

No dudo que comunidades religiosas hayan realizado esta traducción de la afirmación religiosa al lenguaje secular y tampoco dudo que no pocas de ellas lo han hecho en un viaje sin retorno y se han quedado en la razón secular, llegando incluso a secularizar la religión.

El teólogo Olegario González de Cardenal nos ha repetido, en muy variadas ocasiones, que una sociedad libre es aquella en la que prevalece la razón pública sobre la razón privada, el interés general sobre el interés particular, la abertura a un horizonte de universalidad frente a las situaciones exclusivas de grupos o minorías. Un horizonte abierto y la libertad garantizada para todos, dentro de la cual las minorías creadoras realizan sus proyectos, son las condiciones para que una sociedad progrese, tanto en el orden del bienestar y de la justicia como de la convivencia y de la ilusión moral.

Razón pública es el resultante razonable y universalizable de la convergencia de las diversas fuentes de sentido, de justicia, de libertad y de esperanza, tales como la ciencia, el pensamiento, la moral, la religión y la cultura. Corresponde al poder, democráticamente constituido, el acoger, jerarquizar y aplicar los elementos que aportan cada una de esas fuentes y aplicarlas en la situación histórica concreta.

La razón pública no es la ideología de una ciencia, de una religión, de un partido político, sino aquella en la que las fuentes de sentido convergen con sus aportaciones específicas, dentro del marco constitucional, 
con la aceptación de las Declaraciones internacionales de derechos humanos, en el reconocimiento de una historia fundadora de cada nación y de los valores democráticos de libertad e igualdad, en la medida en que derivan de un orden racional respetuoso de las personas y de sus bienes constituyentes. Esa razón pública así pensada es responsabilidad y derecho de todos los ciudadanos: todos debemos aprobarla y compartirla en el gozo de la convivencia, que nunca es reducción a la uniformidad sino cooperación en la diferencia.

No se puede reducir la religión al silencio o excluirla del tejido social, como tampoco imponerla ni introducirla al margen de la legalidad constitucional. Hay que integrar, no solo tolerar, su legitimidad democrática, su participación en el dialogo social, no exigiéndole más ni menos que a los otros protagonistas de la sociedad. Así entendida la razón religiosa es un elemento indispensable de la vida y del diálogo público en la sociedad libre de una España moderna.

\section{Referencias bibliográficas}

Cavanaugh, William T. (2010): El mito de la violencia religiosa. Ideología secular y raíces del conflicto moderno. Granada: Nuevo Inicio.

Habermas, J., Taylor, Ch., Butler, J. y West, C. (2011): El poder de la religión en la esfera pública. Madrid: Trotta (ed. de E. Mendieta y J. Vanantwerpen).

MacIntyre, A. (2008): Ética y política. Granada: Nuevo Inicio.

Ratzinger, J. y Habermas, J. (2006): Dialéctica de la secularización. Sobre la razón y la religión. Madrid: Encuentro. 



\section{Principios de narratividad en El Eclipse (1907) de George Méliès}

\section{Principles of Narrativity in The Eclipse (1907) by Georg Méliès}

Victoria Pérez. Instituto de Ciencias Sociales y Humanidades, BUAP, México

Resumen:

En esta investigación interdisciplinaria realizamos un análisis narratológico y cinematográfico de la película El Eclipse (1907) producida por George Méliès. A fin de identificar los principios de narratividad en esta cinta, analizamos sus planos, los escenarios y los cortes. Los resultados muestran que la linealidad en la presentación de los acontecimientos se interrumpe mediante unos planos insertados que funcionan como elipsis.

Palabras clave:

Cine, plano, elipsis, narratividad.

Abstract:

In this interdisciplinary study we report a narratological and cinematographic analysis of the film The Eclipse (1907), produced by George Méliès. In order to identify the principles of narrativity in this film, we examine its shots, settings and cuts. Our results show that the linearity in the presentation of events is interrupted by the insertion of shots that act as ellipsis.

Key words:

Film, Shot, Ellipsis, Narrativity. 